Please note that this draft may not be identical with the published version.

Yamaguchi, M. (2019). What 100 years of typing research can tell us. Cognitive Bulletin, 4, 25-33.

What 100 Years of Typing Research Can Tell Us

Motonori Yamaguchi

Edge Hill University 


\section{What 100 Years of Typing Research Can Tell Us}

The need of typewriting skill is ever increasing in our lives. The prevalence of personal computers and mobile devices has transformed the way people communicate with each other. Although many different types of human interfaces have been introduced over the decades, the dominant form of computer interface remains to be that of typing on a keyboard. In personal communication, emailing and texting through the Internet have largely replaced writing a letter and posting it for delivery. Young children can start learning to type on their parents' computers even before they start learning hand-writing in school. Whilst typing has become one of the common everyday skills within the last two decades, experimental psychologists have been studying it as a research subject for more than a hundred years. The first experimental study of typewriting skill appeared in 1904 (Swift, 1904), and a monograph that was devoted solely to psychology of typing skill was published in 1908 (Book, 1908). Since then, this subject has been of continued interest for many experimental psychologists, which include leading figures of cognitive sciences (e.g., Gentner, 1987; Hill, Rejall, \& Thorndike, 1913; Lashley, 1951; Logan \& Crump, 2011; Shaffer \& Hardwick, 1968; Rabbit, 1978; Rumelhart \& Norman, 1982; Salthouse, 1986). Apart from its practical importance in the modern lifestyle, the act of typing involves the right amount of complexity as well as well-defined and measurable actions. These features of typewriting makes it an ideal testbed to gain our understanding of the control and acquisition of complex skills. This review article first presents a brief overview of the classic studies of typewriting skill in the early $20^{\text {th }}$ century, discusses the developments that took place after the mid-20 $0^{\text {th }}$ century, and concludes with the current status and issues that remain for future investigations in the $21^{\text {st }}$ century. 


\section{Classic Studies on Typewriting Habits in the Early $20^{\text {th }}$ Century}

Classic studies on typewriting skill focused on learning. Researchers observed the improvement of typewriting skill over practice and reported interesting characteristics of the skill (Bradford, 1915; Chapman, 1919; Hill et al., 1913; Hoke, 1921; Towne, 1922). Fenderick (1937) took a different path and became one of the first researchers who used a clever experimental manipulation to reveal how typing habits changed according to the proficiency levels of typists. Prior to his experiment, Bryan and Harter (1899) studied telegraphic skill and suggested that trainees first used individual letters as the working units of their telegraphing but gradually shifted to words as their skills improved. In the monograph on typing skill, Book (1908) also noted similar shifts of typewriting habits from letters to words, and even to phrases as typing skill improved.

Fenderick (1937) examined these observations experimentally. He recruited typists with various skill levels and asked them to type a set of sentences (see Table 1 for examples). In some of the sentences, he scrambled the order of letters within words, which destroyed the word meanings, so that typists could not work on words as the unit of typewriting; in other sentences, he scrambled the orders of words within sentences, which destroyed the meanings of the sentences but not those of words, so that typists could not work on phrases as the unit of typewriting. His results showed that scrambling letter orders impaired performance of skilled typists to a much greater degree than that of less skilled typists, suggesting that words served as an important unit of skilled typewriting. However, the impact of scrambling word orders on skilled typists was no greater than that on less skilled typists. Such outcome implies that linguistic units larger than words were not critical even for highly skilled typists. 
Table 1. Examples of sentences used in Fenderick's (1937) experiment.

\begin{tabular}{ll}
\hline Type of Sentence & Example \\
\hline Normal sentence & "You will remmeber our early..." \\
Word scrambled & "Us talk wanted to with..." \\
Letter scrambled & "Uyo llwi emrebmer uro..." \\
\hline
\end{tabular}

Only five years prior to Fenderick's experiment, Butch (1932) published a study that examined the "eye-hand span" for typists with various skill levels. When transcribing a text, typists usually look ahead of the text that they are copying. Thus, the eye position is usually ahead of the letter that is being typed at the moment. The eye-hand span is the number of letters between the position of eye fixation on a text and the position of the letter being typed at a given moment. Butch found that the eye-hand span increased as skill levels improved, suggesting that more skilled typists looked ahead more letters than less skilled typists. Nevertheless, Butch also found that the eye-hand span only ranged from 4 letters for moderately skilled typists to 7 letters for highly skilled typists. This range is no more than the typical lengths of common words; thus, skilled typists could anticipate the forthcoming text more efficiently than less skilled typists could, but their anticipation did not seem to go much beyond a single word.

These classic studies indicate that words are an important unit of typing skill, but linguistic units above words may not be consequential even for highly skilled typists. These findings provided an important implication for contemporary theories of skilled typewriting (e.g., Logan \& Crump, 2011), which will be discussed further in a later section. Although these findings established the basic foundations for the current understanding of typing skill, there were a few decades of blank period in the 
early $20^{\text {th }}$ century, which corresponded roughly to the time of radical behaviourism that dominated experimental psychology. The interest in typewriting skill as a research subject resurged in the midway to the century.

\section{Cognitive Approaches to Typing Skill in the Mid-20 ${ }^{\text {th }}$ Century}

At the dusk of the behaviourist era, one of the earliest consideration of typing skill as a research subject appeared in Lashley's (1951) paper presented at a symposium and was published later as a book, which is of a historical importance of its own as it challenged radical behaviourism of his time. The main thesis of his argument was the problem of serial order in behaviour. He argued that sequential behaviours including speaking, typing, and walking, are too complex to organise based on behaviourist theories of associative chain, according to which each action triggered the next action in a sequence. Although Lashley's thesis offered an important insight that contributed to later developments of cognitive theories of skilled typewriting (e.g., Logan \& Crump, 2011; Rumelhart \& Norman, 1982), he only mentioned typing as one of anecdotal evidence to refute the associative chain theories but did not report any experimental work of his own on typing skill.

Hershman and Hillix's (1965) study was perhaps the first study that brought typing skill back to experimental psychology in the 1960s. While adopting Fenderick's (1937) manipulation of scrambling word and letter orders, these researchers developed a 'preview' method in which the number of letters ahead of the current typing position was controlled. In this procedure, typists could only see one, two, three, or six letters that were to be typed after the current letter. This restricted preview slowed the speed of typing. More importantly, it also revealed that previewing more than six letters ahead of the current typing position did not facilitate the typing speed much when copying normal sentences or sentences with scrambled 
word orders, whereas previewing more than three letters did not facilitate the typing speed when copying sentences with random strings. These observations implied two important facts. First, skilled typists looked ahead of more letters in sentences with intact words than in sentences with random strings (six letters ahead vs. three letters ahead). Second, skilled typists did not look ahead beyond a single word even when typing normal sentences. The latter finding agrees with Fenderick's finding that words serve as the working unit for skilled typists but not for less skilled typists.

Several eminent psychologists entered the field of typing skill research during the next three decades, one of the leading figures being Shaffer: He first extended Fenderick's (1937) findings with scrambled sentences by including units smaller than words, such as syllables (Shaffer \& Hardwick, 1968; Shaffer \& Hardwick, 1969a), and showed that they also serve important units of typing. He also examined influences of other factors, such as word length (Shaffer \& Hardwick,1969b). Shaffer used Hershman and Hellix's (1965) preview technique (Shaffer, 1973; Shaffer \& French, 1971; Shaffer \& Hardwick, 1970) and replicated the basic findings that words were the important unit of skilled typewriting but linguistic units above words were not. Shaffer's work expanded typing skill research to new topics, such as error detection (Shaffer \& Hardwick, 1969a; see also West, 1967) and error latency analyses (Shaffer, 1975a), and the control structure of typing performance (Shaffer, 1978, 1982). During this period, he also published an important dual-task study (Shaffer, 1975b), which suggested that a highly skilled typist could copy-type a text while reciting another text spoken to her with little dual-task interference. This is known as perfect time-sharing (Schumacher et al., 2001) that remains to be an important topic in the contemporary dual-tasking literature (see Yamaguchi, Logan, \& Li, 2013). 
In 1980s, typing received extensive attention from a group of researchers from the University of California, San Diego; these researchers provided detailed analyses of typing skill at linguistic and motoric levels (see Cooper, 1983). Two members of this group, Rumelhart and Norman, published an influential computational model of skilled typewriting (Rumelhart \& Norman, 1982), which proposed detailed cognitive processes underlying the production of keystroke sequences (see also Gentner, 1987). Consistent with the findings in the classic studies (Fenderick, 1937) and later replications (e.g., Hershman \& Hellix, 1965), the computational model takes a word as its input and decomposes it into individual letters that activate corresponding keystrokes. The main thrust of this computational model was the simulation of the processes that organise keystrokes in a series, which provided a solution to Lashley's (1951) problem of serial order. The model proposed that all keystrokes associated with a word are activated in parallel, rather than each keystroke being activated by the preceding one as a chain, and an order is imposed on the activated keystrokes in terms of inhibition from all preceding keystrokes. Thus, later keystrokes receive stronger inhibition from the preceding keystrokes; this mechanism imposes the correct order of keystrokes without assuming the behaviourist associative chain. However, no specific mechanism was described as to how the information about the keystroke order is represented in the model, which was crucial to create a gradient of inhibition over activated keystrokes.

\section{Typing Research in the $21^{\text {st }}$ Century, and Current Issues}

One of the hallmarks in typing research after the turn of the new millennium is Logan and Crump's (2011) theory of skilled typewriting. Their two-loop theory proposes that typing is controlled by two separate streams of cognitive processes that are organized in a hierarchy (see Figure 1). Each stream forms a feedback loop 
that operates on a specific linguistic unit. The higher level of the hierarchy forms an outer loop operating on the word level that processes and comprehends the language, passes individual words to the lower level, and monitors the word typed on the monitor. The lower level forms an inner loop operating on the letter or keystroke level that decomposes a word into letters, activates and executes the corresponding keystrokes, and receives haptic feedback at the fingertips. Hence, the two loops produce a nested structure that controls different linguistic units.

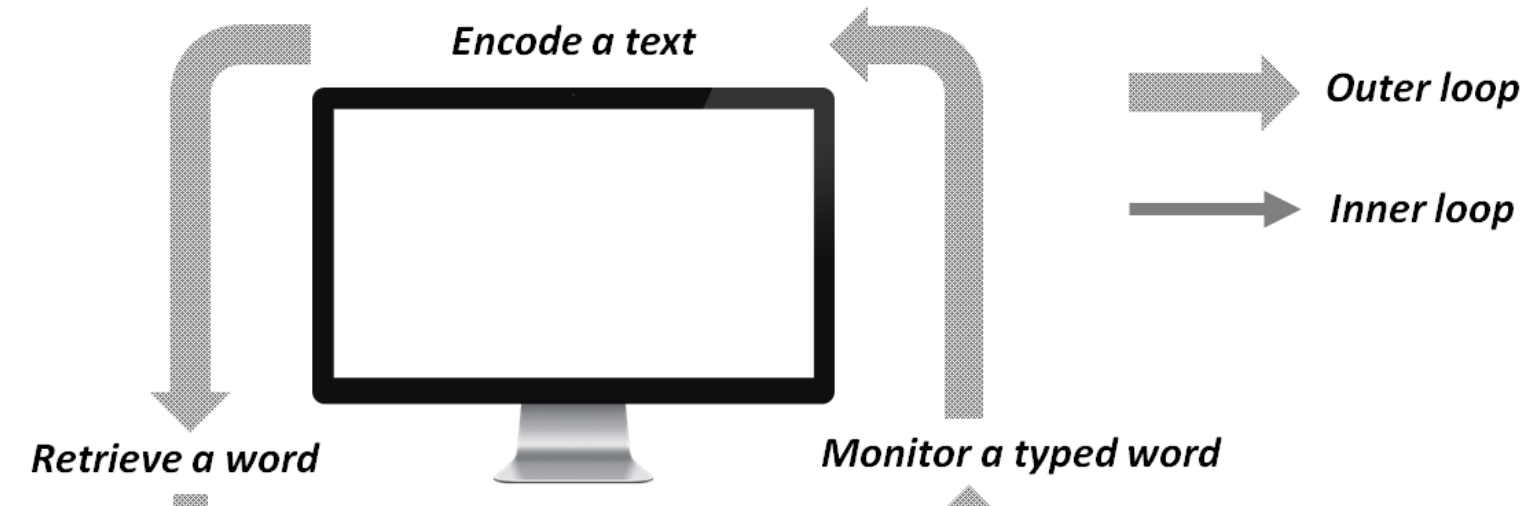

Pass a word to the inner loops

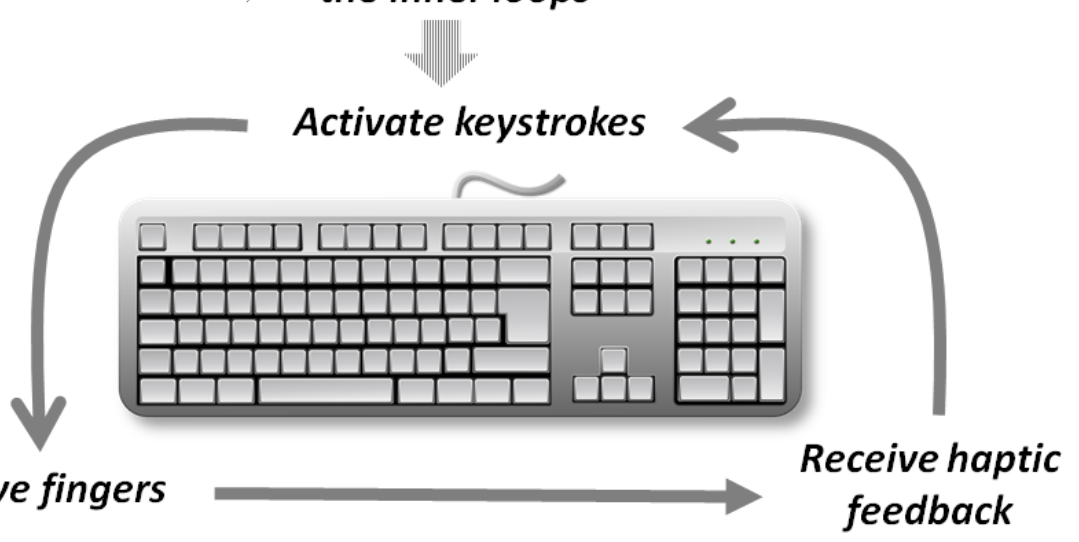

Figure 1. A schematic illustration of Logan and Crump's (2011) two-loop theory of skilled typewriting (also see Yamaguchi, Crump, \& Logan, 2013). 
Logan and Crump (2011) proposed that four observations of skilled typing collectively supported hierarchically structured controlled processes; (1) the two loops are selectively influenced by different factors (e.g., Logan \& Zbrodoff, 1998), (2) the words serve as the interface between the loops (e.g., Crump \& Logan, 2010a), (3) the two loops share little knowledge beyond the words (e.g., Liu, Crump, \& Logan, 2010; Logan \& Crump, 2009), and (4) the two loops rely on different feedback (e.g., Crump \& Logan, 2010b; Logan \& Crump, 2010).

Some of these observations echo the earlier findings that were discussed in the previous sections. For example, Fenderick's (1937) demonstrations in the early $20^{\text {th }}$ century that words serve as an important working unit of skilled typewriting supports the role of words as the interface between the two loops. The research group active in the 1980s also found that lexical and sublexical factors affected typing performance at different levels of typing performance (Gentner, Larochelle, \& Grudin, 1988; also see Pinet, Ziegler, \& Alario, 2016), which supports the selective influences on the two loops. Studies of typing errors in 1960s showed the importance of visual feedback for error recognition (e.g., Shaffer \& Hardwick, 1969a; West, 1967), whereas a physiological study on typing suggested that error-related keystroke latencies depended on haptic feedback (Gordon \& Soechting, 1995). Crump and Logan (2010) demonstrated that these sources of feedback are monitored independently (also see Rieger, Martinez, \& Wenke, 2011; Snyder, Logan, \& Yamaguchi, 2015).

The two-loop theory, thus, serves as an integrative framework to provide a cohesive account of many discrete findings within the last hundred years of typing research. Nevertheless, as is always the case in any field of experimental psychology, there are still outstanding questions to be addressed within the 
framework. Three issues are considered here: First, the two-loop theory provides a general overview, but it does not specify detailed mechanisms and computations that have to take place within each of the loops. Second, the theory does not make it clear as to how the hierarchical control emerges over training with typing skill. Third, there are mixed empirical supports for the strict separation between different levels of the hierarchy.

Computations within the outer and inner loops. Logan (2018) recently proposed a computational account of typing performance, which partly addresses the first issue of the computations within the two-loop theory. The model is formally borrowed from a context model of episodic memory retrieval (Howard \& Kahana, 2002) and conceptually resembles recurrent network models of sequential behaviour (e.g., Elman, 1990; Jordan, 1986). The main idea is that a memory trace or action is retrieved based on the current input and context that represents the retrieved items preceding the current item. In Logan's model (named Context Retrieval and Updating, or $\mathrm{CRU})$, the context consists of the two levels of representations, words and letters. The word level context stores the word to be typed at the moment, and the letter level context stores letters in the word that have been typed. The combination of the current word and the typed letters then specifies and retrieves a letter to be typed next. The retrieval of a letter depends on the similarity between the current context and the stored instances of contexts that have been experienced in the past.

The CRU model is not a full computational account of the two-loop theory; as Logan suggested, it represents the operations within the inner loop (i.e., retrieval of a keystroke sequence). The model makes a good comparison to that of Rumelhart and Norman's (1982), in which mutual inhibition of keystrokes plays a central role in 
realising the correct order of keystrokes. The CRU does not assume inhibition between keystrokes, but it still realises the correct serial order that emerges based on the context retrieval operation. It provides a solution to Lashley's (1951) problem of serial order in behaviour. Nevertheless, like Rumelhart and Norman's model, the CRU has left out computations within the outer loop.

Development of hierarchical control. It is worth reminding that most of the classic studies on typewriting skill in the early $20^{\text {th }}$ century concerned about the acquisition processes of the skill (e.g., Book, 1908; Swift, 1904), although more recent work focused on the control of the skill (e.g., Logan \& Crump, 2011; Rumelhart \& Norman, 1982; Salthouse, 1986). The recent investigations on the emergence of hierarchical structures are based on the idea of chunking (Yamaguchi \& Logan, 2014b) and were carried out by having skilled typists to practice typing unfamiliar materials (nonwords; Yamaguchi \& Logan, 2016; Yamaguchi, Randle, Wilson, \& Logan, 2017) or familiar materials with an unfamiliar context (a keyboard with substituted key positions; Yamaguchi \& Logan, 2014a). Although Logan (2018) emphasised that the $\mathrm{CRU}$ requires no representation that specifies a sequence of keystrokes, it still requires higher-level representations that are associated with a unique group of keystrokes. Such higher-level representations must be learned and constructed by chunking lower level representations (letters or keystrokes) into a unit as typists are trained with unfamiliar materials or contexts.

Chunking can be revealed at different levels of cognitive processes during typing, including encoding texts, selecting a keystroke sequence, and implementing keystrokes (Yamaguchi \& Logan, 2014b), and different levels of linguistic units (letters, bigrams, and words) contribute to the formation of chunks (Yamaguchi \& Logan, 2014a), presumably at different levels of skill proficiency (e.g., Fenderick, 
1937; Shaffer \& Hardwick, 1968). Interestingly, studies suggest that the formation of chunks depends on whether prior typing episodes of the materials could be reminded at the time when the same materials are being typed later (Yamaguchi et al., 2016, 2017). Although these findings are still preliminary as compared to a fully developed computation account that is intended as a future endeavour, the concept of chunking is most likely to play an important role in advancing our understanding of the computations underlying the acquisition of typewriting skill.

The interface between the two loops. The two-loop theory proposes that the interface between the two loops are words, and the two loops share little knowledge beyond the words (Logan \& Crump, 2010). However, recent studies also suggested that the two loops might have closer interactions to play. For instance, studies showed that there are influences of how to practice writing (handwriting or typing) on subsequent memory of letters or shapes (Longcamp, Boucard, Gilhodes, \& Velay, 2006; Longcamp et al., 2008; Longcamp, Zerbato-Poudou, \& Velay, 2005). An electrophysiological study also suggested overlapped brain activities between semantic and motor processes during typing of picture names (Pinet, Dubarry, \& Alario, 2016), although another electrophysiological study suggested a separation between them (Scaltritti, Pinet, Longcamp, \& Alario, 2017). Others found that skilled typists tend to prefer letter pairs that were typed with different hands over pairs that were typed with the same hand, even if typing is not directly relevant to the preference judgment (Beilock \& Holt, 2007), and this preference appears to rely on the ease of typing the former pairs (Kozlik, 2014). In a choice reaction task with the left- and right-hand fingers, skilled typists responded faster to the colours of letters if the responding hand matched the hand that was usually used to type the letters than when it did not match (Rieger, 2004). Although none of these findings would 
seriously undermine the assumptions of the two-loop theory, it is not clear whether the two-loop theory would predict them. Importantly, these studies do raise questions of how the two loops are interfaced and to what extent they could influence the operations of the other loop. A recent study found that the speed and accuracy of typing performance may be controlled by the outer loop, but the control was effected in the inner loop (Yamaguchi, Crump, \& Logan, 2013). It was also found that both loops make use of limited resources in selecting words or letters (Yamaguchi, Logan, \& $\mathrm{Li}, 2013)$, but it is unclear as to whether they share the same resources or embody separate pools of resources. The issue of how the two loops collaborate in executing skilled typewriting is a domain that requires more scrutiny in future investigations.

\section{Conclusion}

Over one hundred years of typing research, typing devices have changed from mechanical typewriters to digital computers, and it has become more common everyday skills than it used to be two decades ago. Nevertheless, many of the findings and observations made on mechanical typewriters in the $20^{\text {th }}$ century remain relevant to the contemporary understanding of typewriting skill with computer keyboards in the $21^{\text {st }}$ century. Typing skill is a rife with a variety of cognitive processes, and it offers a rich opportunity to integrate different theories of human cognition from seemingly separate research domains. Such an integrative effort must be made more frequently and extensively in cognitive psychology. Typing skill is well-defined and can be measured precisely, which are difficult with other complex skills. Importantly, many people are highly skilled in typing on a keyboard nowadays, as they start typing relatively early in their age and continue using it throughout their lifetime. A better understanding of how it works can make differences in people's lives. 


\section{References}

Beilock, S. L., \& Holt, L. E. (2007). Embodied preference judgments: Can likeability be driven by the motor system? Psychological Science, 18, 51-57.

Book, W. F. (1908). The psychology of skill, with special reference to its acquisition in typewriting. Missoula, MT: University of Montana.

Butsch, R. L. (1932). Eye movements and the eye-hand span in typewriting. Journal of Educational Psychology, 23, 104-121.

Bryan, W. L., \& Harter, S. N. (1899). Studies on the telegraphic language: The acquisition of a hierarchy of habits. Psychological Review, 6, 345-375.

Cooper, W. E. (1083). Cognitive aspects of skilled typewriting. New York: Springer.

Crump, M. J. C., \& Logan, G. D. (2010a). Hierarchical control and skilled typing: Evidence for word level control over the execution of individual keystrokes. Journal of Experimental Psychology: Learning, Memory, and Cognition, 36, 1369-1380.

Crump, M. J. C., \& Logan, G. D. (2010b). Warning, this keyboard will de-construct: The role of the keyboard in skilled typewriting. Psychonomic Bulletin and Review, 17, 394-399.

Dvorak, A. (1943). There is a better typewriter keyboard. National Business Education Quarterly, 12, 51-58.

Elman, J. L. (1990). Finding structure in time. Cognitive Science, 14, 179-211. Fendrick, P. (1937). Hierarchical skills in typewriting. Journal of Educational Psychology, 28, 609-620.

Gentner, D. R. (1987). Timing of skilled motor performance: Tests of the proportional duration model. Psychological Review, 94, 255-276. 
Gentner, D. R., Larochelle, S., \& Grudin, J. (1988). Lexical, sublexical, and peripheral effects in skilled typewriting. Cognitive Psychology, 20, 524-548.

Gordon, A. M., \& Soechting, J. F. (1995). Use of tactile afferent information in sequential finger movements. Experimental Brain Research, 107, 281-292.

Hill, L. B., Rejall, A. E., \& Thorndike, E. L. (1913). Practice in the case of typewriting. Journal of Genetic Psychology, 20, 516-529.

Hoke, R. E. (1921). The improvement of speed and accuracy in typewriting (PhD Thesis). Baltimore, MD: Johns Hopkins University.

Howard, M. W., \& Kahana, M. J. (2002). A distributed representation of temporal context. Journal of Mathematical Psychology, 46, 269-299.

Jordan, M. I. (1986). Serial order: A parallel distributed processing approach (tech report). University of California, Institute for Cognitive Science.

Kozlik, J. (2014). Preferring alphabet-keyboard compatibility: Congruency between spatial codes shapes the affective connotation of letters. Journal of Cognitive Psychology, 26, 520-529.

Lashley, K. S. (1951). The problem of serial order in behaviour. In L. A. Jeffress (Ed.), Cerebral mechanisms in behaviour (pp. 112-136). New York: Wiley.

Liu, X., Crump, M. J. C., \& Logan, G. D. (2010). Do you know where your fingers have been? Explicit knowledge of the spatial layout of the keyboard in skilled typists. Memory and Cognition, 38(4), 474-484.

Logan, G. D. (2018). Automatic control: How experts act without thinking. Psychological Review, 125, 453-485.

Logan, G. D., \& Crump, M. J. C. (2009). The left hand doesn't know what the right hand is doing: The disruptive effects of attention to the hands in skilled typewriting. Psychological Science, 20, 1296-1300. 
Logan, G. D., \& Crump, M. J. C.(2010). Cognitive illusions of authorship reveal hierarchical error detection in skilled typists. Science, 330, 683-686.

Logan, G. D. \& Crump, M. (2011). Hierarchical control of cognitive processes: The case for skilled typewriting. In Brian Ross (Ed.). The Psychology of Learning and Motivation, Vol. 54. (pp.1-27). Burlington: Academic Press.

Logan, G. D., \& Zbrodoff, N. J. (1998). Stroop type interference: Congruity effects in color naming with typewritten responses. Journal of Experimental Psychology: Human Perception and Performance, 24, 978-992.

Longcamp, M., Boucard, C., Gilhodes, J.-C., Anton, J.-L., Roth, M., Nazarian, B., \& Velay, J.-L. (2008). Learning through hand- or typewriting influences visual recognition of new graphic shapes: Behavioral and functional imaging evidence. Journal of Cognitive Neuroscience, 20, 802-815.

Longcamp, M., Boucard, C., Gilhodes, J.-C., \& Velay, J.-L. (2006). Remembering the orientation of newly learned characters depends on the associated writing knowledge: A comparison between handwriting and typing. Human Movement Science, 25, 646-656.

Longcamp, M., Zerbato-Poudou, M.-T., \& Velay, J.-L. (2005). The influence of writing practice on letter recognition in preschool children: A comparison between handwriting and typing. Acta Psychologica, 119, 67-79.

Pinet, S., Dubarry, A.-S., \& Alario, F.-X. (2016). Response retrieval and motor planning during typing. Brain and Language, 159, 74-83.

Pinet, S., Ziegler, J. C., \& Alario, F.-X. (2016). Typing is writing: Linguistic properties modulate typing execution. Psychonomic Bulletin \& Review, 23, 1898-1906.

Rabbit, P. M. A. (1978). Detection of errors by skilled typists. Ergonomics, 21, 945958. 
Rieger, M. (2004). Automatic keypress activation in skilled typing. Journal of Experimental Psychology: Human Perception and Performance, 30, 555-565.

Rieger, M., Martinez, F., \& Wenke, D. (2011). Imagery of errors in typing. Cognition, $121,163-175$.

Rumelhart, D. E., \& Norman, D. A. (1982). Simulating a skilled typist: A study of skilled cognitive-motor performance. Cognitive Science, 6, 1-36.

Salthouse, T. A. (1986). Perceptual, cognitive, motoric aspects of transcription typing. Psychological Bulletin, 99, 303-319.

Scaltritti, M., Pinet, S., Longcamp, M., \& Alario, F.-X. (2017). On the functional relationship between language and motor processing in typewriting: An EEG study. Language, Cognition, and Neuroscience, 32, 1086-1101.

Schumacher, E. H., Seymour, T. L., Glass, J. M., Fenscik, D. E., Lauber, E. J., Kieras, D. E., \& Meyer, D. E. (2001). Virtually perfect time sharing in dual-task performance: Uncorking the central cognitive bottleneck. Psychological Science, 12, 101-108.

Shaffer, L. H. (1973). Latency mechanisms in transcription. In S. Kornblum (Ed.), Attention and performance IV (pp. 435-446). New York: Academic Press. Shaffer, L. H. (1975a). Control processes in typing. Quarterly Journal of Experimental Psychology, 27, 419-432.

Shaffer, L. H. (1975b). Multiple attention in continuous verbal tasks. In P. M. A. Rabbitt \& S. Dornic (Eds.), Attention and performance $V$ (pp. 157-167). New York: Academic Press.

Shaffer, L. H. (1978). Timing in the motor programming of typing. Quarterly Journal of Experimental Psychology, 30, 333-345.

Shaffer, L. H. (1982). Rhythm and timing in skill. Psychological Review, 89, 109-122. 
Shaffer, L. H., \& French, A. (1971). Coding factors in transcription. Quarterly Journal of Experimental Psychology, 23, 268-274.

Shaffer, L. H., \& Hardwick, J. (1968). Typing performance as a function of text. Quarterly Journal of Experimental Psychology, 20, 360-369.

Shaffer, L. H., \& Hardwick, J. (1969a). Errors and error detection in typing. Quarterly Journal of Experimental Psychology, 21, 209-213.

Shaffer, L. H., \& Hardwick, J. (1969b). Reading and typing. Quarterly Journal of Experimental Psychology, 21, 381-383.

Shaffer, L. H., \& Hardwick, J. (1970). The basis of transcription skill. Journal of Experimental Psychology, 84, 424-440.

Snyder, K. M., Logan, G. D., \& Yamaguchi, M. (2015). Watch what you type: The role of visual feedback from the screen and hands in skilled typewriting. Attention, Perception, \& Psychophysics, 77, 282-292.

Swift, E. J. (1904). The acquisition of skill in type-writing; A contribution to the psychology of learning. Psychological Bulletin, 1, 295-305.

Towne, B. M. (1922). An individual curve of learning: A study in typewriting. Journal of Experimental Psychology, 5, 79-92. (Reprinted in 1991).

West, L. J. (1967). Vision and kinesthesis in the acquisition of typewriting skill. Journal of Applied Psychology, 51, 161-166.

Yamaguchi, M., Crump, M. J. C., \& Logan, G. D. (2013). Speed-accuracy trade-off in skilled typewriting: Decomposing the contributions of hierarchical control loops. Journal of Experimental Psychology: Human Perception and Performance, 39, 678-699.

Yamaguchi, M., \& Logan, G. D. (2014a). Pushing typists back on the learning curve: Contributions of multiple linguistic units in the acquisition of typing 
skill. Journal of Experimental Psychology: Learning, Memory, and Cognition, $40,1713-1732$.

Yamaguchi, M., \& Logan, G. D. (2014b). Pushing typists back on the learning curve: Revealing chunking in skilled typewriting. Journal of Experimental Psychology: Human Perception and Performance, 40, 592-612.

Yamaguchi, M., \& Logan, G. D. (2016). Pushing typists back on the learning curve: Memory chunking in the hierarchical control of skilled typewriting. Journal of Experimental Psychology: Learning, Memory, and Cognition, 42, 1919-1936. Yamaguchi, M., Logan, G. D., \& Li, V. (2013). Multiple bottlenecks in hierarchical control of action sequences: What does "response selection" select in skilled typewriting? Journal of Experimental Psychology: Human Perception and Performance, 39, 1059-1084.

Yamaguchi, M., Randle, J. M., Wilson, T. L., \& Logan, G. D. (2017). Pushing typists back on the learning curve: Memory chunking improves retrieval of prior typing episodes. Journal of Experimental Psychology: Learning, Memory, and Cognition, 43, 1432-1447. 